\title{
Simultaneous Effect of Resistance Training and Portulace Oleraceal Supplementation on Some Biochemical Markers of Bone Dynamics in Womı with Type II Diabetes
}

\section{Shokufe Ziadloo (MSc)}

Department of Exercise Physiology, Sari Branch, Islamic Azad University, Sari, Iran

Parvin_Farzanegi (PhD)

Department of Exercise Physiology, Sari Branch, Islamic Azad University, Sari, Iran

Masoumeh Habibian (PhD)

Department of Physical Education and Sports Sciences, Qaemshahar Branch, Islamic Azad University Qaemshahar, Iran

Corresponding Author: Parvin Farzanegi

Tel: +989112230233

Email: parvin.farzanegi@gmail.com

Address: Department of Exercise Physiology, Sari Branch, Islamic Azad University, Sari, Iran

Received : 17 May 2015

Revised: 11 Aug 2015

Accepted: 19 Aug 2015

\begin{abstract}
Background and Objective: 0steoporosis is one of the complications of diabetes. The aim of this study was to determine the impact of resistance training along with Portulaca oleracea supplementation on 0PG and NFאB levels (bone markers) in women with type II diabetes.

Methods: 0verall, 28 women with type II diabetes (44 to 60 years old) were randomly and equally assigned into four groups (supplement, training, training-supplement and control). An eight-week resistance training program (three one-hour sessions per week with one repetition maximum) was performed using three types of bands with different resistances, at $40-50 \%$ intensity and 50-70\% maximum heart rate. P. oleracea seeds were supplemented daily (7.5 grams mixed in yogurt) for eight weeks. The data was analyzed using descriptive statistics, paired t-test and ANOVA.

Results: After 8 weeks, OPG and NFKB levels in the three groups of supplement, training and training-supplement increased and decreased, respectively. The highest change in both variables was observed in the training-supplement group. Moreover, the level of these two variables in the training-supplement group had significant difference with the controls and other groups $(\mathrm{P}=0.000)$.

Conclusion: As a non-pharmacological therapeutic approach, the regular resistance training and P. oleracea supplementation can increase bone formation markers and reduce bone resorption in women with type II diabetes.

Keywords: Type II Diabetes, Resistance Training, Portulaca 0leracea, OPG, NFкB.
\end{abstract}




\section{INTRODUCTION}

Diabetes is one of the most common metabolic disorders especially in the elderly, which have debilitating effects on the lives of patients $(1,2)$. Type II diabetes is growing in the world at an alarming rate. It is estimated that the number of diabetic adults in the world will increase to 300 million in 2025 (3). There are currently 1.5 million diabetic patients in Iran. Approximately $85 \%$ of these individuals are type II diabetic patients $(4,5)$. complication (6) and metabolic bone disease, characterized by low bone mass and structural deterioration of bone tissue that leads to increased risk of bone fragility (7). Studies demonstrated high bone resorption rates in both types of diabetes (8). Researchers showed that diabetic women have higher osteoporosis compared to healthy women $(9$, 10). Almost $28 \%$ of women aged over 50 years suffer from osteoporosis (11). Poor diet and therefore receiving less nutrients reduces body storage of iron, calcium, zinc and other essential minerals. The complications caused by these deficiencies will lead to various diseases such as osteoporosis (12).The exact mechanism of bone destruction has not been clearly identified. Recent findings suggested the role of a new molecular system that belongs to tumor necrosis factor (TNF) family in regulation of bone destruction, which includes three key proteins (receptor activator of nuclear factor kappa-B, receptor activator of nuclear factor kappa-B ligand and osteoprotegerin) (13-16). Osteoprotegerin (OPG) is a large glycoprotein that belongs to the TNF $\alpha$ family. This glycoprotein ligand along with receptor activator of nuclear factor kappa-B ligand (RANKL) and its receptor (RANK) form the molecular triad that regulates bone metabolism by controlling osteoclasts. On the other hand, RANKL increases osteoclastogenesis and bone resorption by binding to RANK. OPG neutralizes it and inhibits bone resorption by binding to RANKL (17). As an inhibitor, OPG prevents the RANKL interaction and reduces osteoclastogenesis (18). Nuclear factor kappa-B (NFKB) is a key signaling pathway involved in the early stages of osteoclast differentiation induced by RANKL (19). It is also considered as an evolutionary family that protects transcription factors in response to environmental changes (20).
Various studies have shown that exercise is the basis of type II diabetes treatment (21). It is also indicated that exercise prevents and controls the disease and diabetes-induced osteoporosis $(22,23)$. Additive effects of weight-bearing exercise on bone density are higher than ordinary activities (24). Studies showed that a large amount of body's minerals especially calcium are excreted during endurance activities, which activates osteoclasts and increases the uptake of calcium from bone tissue. Meanwhile, resistance training is a safe stimulant of bone formation because of the high pressure that it exerts on bones (25). Long-term resistance training can decrease the osteoclastic process and reduce diabetes-induced osteoporosis (26). Recent studies considered medicinal plants useful in treatment of type II diabetes. Some medicinal plants have beneficial effects on bone markers, and are considered as alternative treatment strategy for diabetesinduced osteoporosis (27). Due to its several properties and by controlling the amount of fact oxidation, Portolaca oleracea can show antioxidant and anti-inflammatory effects (28, 29). P. oleracea L. is a grass-like plant with small yellow flowers that grows widely in various regions of the world (30). Because of its various constituents such as flavonoids, $P$. oleracea show beneficial effects on type II diabetes (31). It also has a beneficial effect in reducing osteoporosis. This plant is a remarkable source of minerals including calcium and phosphorus, which could have potential role in prevention of bone disorders such as osteoporosis $(32,33)$. Numerous studies have been conducted on bone markers and the effect of physical activity in diabetics. However, the simultaneous impact of exercise and herbal supplementation has been studied less. Therefore, this study aimed to determine the effect of a period of resistance training along with $P$. oleracea supplementation on bone markers (OPG and NFkB) in women with type 2 diabetes.

\section{MATERIALS AND METHODS}

Participants

This was a semi-experimental study (clinical trial registration number: 2015051772494) with a pretest-posttest design and a control group. The study population included all type 
II diabetic women in Sari, Iran. The female volunteers were identified and 28 of them who met the inclusion criteria were enrolled in the study. The age of participants ranged from 44 to 60 years. They had no regular exercise, no supplementation and none of the chronic or acute diabetic complications. Their blood glucose level was higher than 126 $\mathrm{mg} / \mathrm{dL}$, and they were taken metformin to lower blood glucose. Written consent was obtained from each participant before the start of the study and the ones who were unwilling to participate were allowed to leave at any stage. The participants were randomly divided into four groups of training, supplement, training-supplement and control (each group included seven individuals) and they were almost matched with age and body mass index (BMI) (Table1).

Resistance training program

Progressive resistance training was performed in groups, three times a week (one hour per session) for eight weeks with 40 to $50 \%$ intensity (one-repetition-maximum), and using three types of resistance bonds. The activities included biceps, triceps, upright row, shoulder press, rowing, side bending, leg press, thigh bending, and quadriceps and hamstrings workouts. In the first two weeks, the trainings included 15 minutes warm up, 30 minutes workout and 15 minutes cool-down $(28,23)$.

\section{$P$. oleracea supplementation}

The supplement group and trainingsupplement group received 7.5 grams of $P$. oleracea seed mixed in 40 grams of yogurt daily with meals (2.5 grams with lunch and 5.2 grams with dinner) for eight weeks. The supplement was prepared weekly in the city of Sari and then weighed and packed for week consumption by the experimental groups. The supplements were provided to the subjects along with necessary recommendations for the amount and timing of consumption. The amount of $P$. oleracea used in this study was calculated based on the average amount of $P$. oleracea seeds consumed in some areas. The necessary recommendations for the amount and timing of consumption were reminded. Moreover, a 2500-3000 kcal daily diet was recommended, which contained 50-55\% carbohydrates, $25-30 \%$ fat and $10-15 \%$ protein $(29,31)$.

Blood sampling and biochemical analysis
Blood samples were taken before and after the interventions, followed by 12 hours of overnight fasting. For this purpose, $7 \mathrm{ml}$ of blood were taken in the laboratory from the left brachial vein of each subject, between 8 to 10 am and after a half-hour break. Post-test sampling was performed 48 hours after stopping resistance training and taking supplements. The plasma was separated and frozen at $-80{ }^{\circ} \mathrm{C}$ in order to measure the level of OPG and NFkB. OPG was measured by ELISA and Cusabio kits (China). NFkB was measured using commercial kits (Cayman, USA).

Statistical analysis

The data was first described in terms of central tendency and distribution. Kolmogorov-Smirnov and Levene test were used to determine normality of data distribution and the homogeneity of variances, respectively. Paired t-test was used to evaluate the variations within groups and one-way analysis of variance (ANOVA) was used to compare the means of study variables in the pre- and post-test stages. In addition, Tukey post hoc test was used to detect differences. Pvalue less than 0.05 was considered as statistically significant.

All statistical analyses were performed by SPSS version 16.

\section{RESULTS}

After the eight-week intervention, OPG level significantly increased in subjects in the supplement (16.63\%), resistance training $(18.75 \%)$ and resistance training-supplement $(30.63 \%)$ groups $(\mathrm{P}=0.000)$. The control group remained almost unchanged (Figure 1). The results of ANOVA showed that factors of time, group and the interaction between these two had a significant impact on OPG level $(\mathrm{P}=0.000)$. Overall, these findings showed that concurrent supplementation and resistance training was more effective on OPG level than the other groups. The results showed that $\mathrm{NF \kappa B}$ level decreased significantly by $13.81 \%$ after eight weeks of $P$. oleracea supplementation, $14.02 \%$ after eight weeks of resistance training and $32.84 \%$ in the exercise-supplement group $(\mathrm{P}=0.000)$. The control group remained unchanged. The results of ANOVA showed that both factors of time and group as well as the interaction between these two factors have a significant effect on NFKB level $(\mathrm{P}=0.000)$, with a higher effect observed in the training-supplement group. 
Table 1- Mean and standard deviation (SD) of body composition indices in the study groups

\begin{tabular}{cccc}
\hline $\begin{array}{c}\text { Index } \\
\text { Group }\end{array}$ & Height $(\mathrm{Cm})$ & Weight(Kg) & Age( Years) \\
\hline Training & $\mathbf{1 5 9 . 2 8} \pm 5.08$ & $\mathbf{7 6 . 2 9} \pm 4.39$ & $\mathbf{5 3 . 2 8} \pm 1.7$ \\
Supplement & $\mathbf{1 5 9 . 1 7} \pm 6.65$ & $\mathbf{7 3 . 5} \pm 4.89$ & $\mathbf{5 2 . 3} \pm 4.08$ \\
Training-supplement & $\mathbf{1 5 9 . 5 7} \pm 5.25$ & $\mathbf{7 5 . 7 1} \pm 5.71$ & $\mathbf{5 2 . 5 7} \pm 2.7$ \\
Control & $\mathbf{1 6 0 . 6 7} \pm 6.54$ & $\mathbf{7 5 . 6 7} \pm 9.44$ & $\mathbf{5 0 . 1 7} \pm 5.34$ \\
\hline
\end{tabular}

Table 2- Changes in the measured variables between 4 groups before and after 8 weeks.

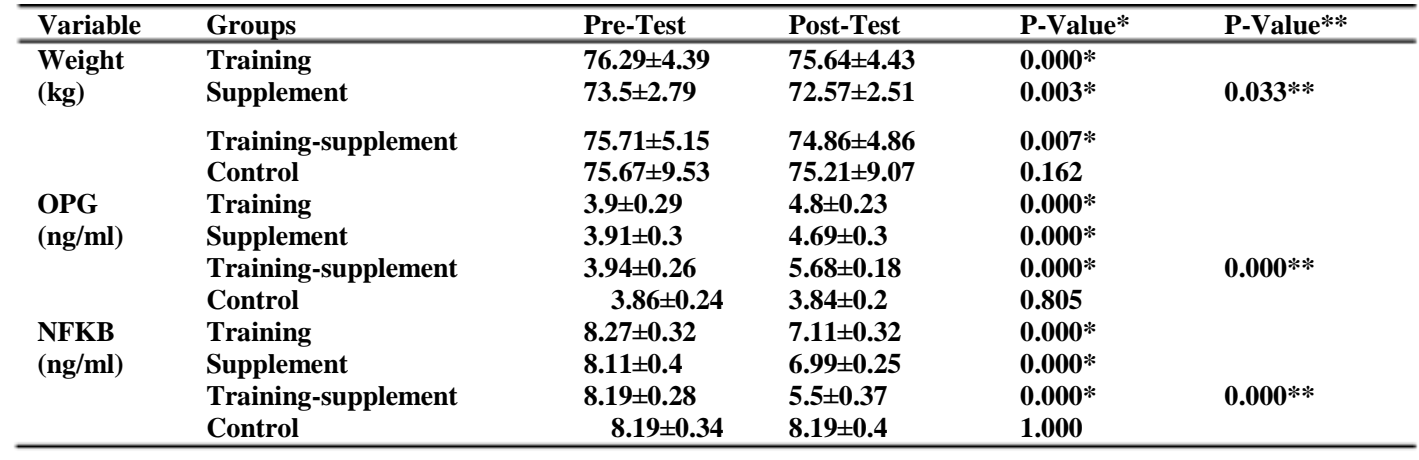

*changes of variables within groups; ** changes of variables between groups

\section{DISCUSSION}

Many studies have shown that diabetes is an important risk factor for osteoporosis (34, $35)$. Some studies show a direct correlation between bone density and insulin dosage (36). The first findings of the present study showed that level of OPG significantly increased after eight weeks in the supplement $(16.63 \%)$, training $(18.75 \%)$ and training-supplement (36.63\%) groups. OPG is an anti-inflammatory protein derived from osteoblasts that stimulates osteogenesis (37). Yasuda et al. investigated the effect of OPG on mice with osteoporosis and reported that injection of $100 \mathrm{mmol} \mathrm{OPG}$ for four weeks can play an important role in the process of bone calcification, and prevent the osteoclastic process (38). Physical activity is considered a good source for bone turnover, and is recommended for prevention of osteoporosis. The OPG level increases after resistance training leading to prevention of osteoporosis process. Some studies have shown that stimulation of osteoblastic or osteoclastic activity is exercise-dependent (22, 39, and 40). Study of Bergström et al. on postmenopausal women showed that a period of aerobic exercise significantly increases OPG level in the exercise group. Meanwhile, the amount of RANKL in this group decreased, and the rate of osteoporosis in the control group was higher than the training group after a year (22).
Various studies show that high pressure in resistance trainings is a safe stimulus to osteogenesis. Exercise training increases osteoblastic activity and OPG level by exerting mechanical pressure on bones. Increased serum OPG level after a period of exercise neutralizes the increased osteoclastic activity $(22,41)$. Study of Marques et al. indicated that eight months of resistance training increases bone mineral density, while OPG and RANKL remain unchanged after resistance training and aerobic exercise (42). This is inconsistent with the findings of the present study, which could be due to differences in intensity, duration and type of trainings, as well as physical fitness and age of the participants in the two studies $(43,44)$. Some studies have also shown that medicinal plants, as dietary supplements are good source of minerals such as calcium that also increase calcium absorption rate. Medicinal plants increase osteoblastic activity and ultimately reduce osteoporosis by increasing the level of OPG (45). In this study, eight weeks of $P$. oleracea consumption significantly increased OPG. It is reported that calcium and phosphorus present in $P$. oleracea have an essential role in normal and better functioning of the bone structure. Moreover, antioxidant 
components of $P$. oleracea activate calciumdependent paraoxonase 1 enzyme. Thus, $P$. oleracea is also effective on intracellular calcium and in this way may activate the bone formation factors $(44,46)$. In this regard, Gao et al. indicated that $P$. oleracea supplementation for 12 weeks inhibits bone resorption, and increases calcium and OPG activity (43). In the present study, eight weeks of supplementation, training and supplementation in combination with resistance training significantly reduced $\mathrm{NF} \kappa \mathrm{B}$ levels by $13.81 \%, 14.02 \%$ and $32.84 \%$, respectively. In fact, the reduction of $\mathrm{NF \kappa B}$ indicates the decreased activity of the osteoclastic cells (47). Diabetic patients are more susceptible to osteoporosis compared to healthy individuals, which may be due to increased activity of $\mathrm{NF \kappa B}$. In this regard, Austin et al. found that increased NFKB level increases the osteoclastic activity (47). By changing the level of RANK, RANKL and $\mathrm{OPG}$, and imbalancing in the expression of these molecules, osteoporosis increases $\mathrm{NF} \kappa \mathrm{B}$, osteoclast formation and ultimately bone resorption $(48,49)$. Recent studies show that resistance training can help prevent the process of osteoporosis by reducing the activity of $\mathrm{NF} \kappa \mathrm{B}$. In this regard, Bergström et al. showed that a one-year period of exercise significantly decreased the activity of $\mathrm{NF \kappa B}$ and RANKL in postmenopausal women (40). It seems that both resistance training and aerobic exercise have similar impact on the osteoclastic process, so that the mechanical pressure of resistance training on bones changes the osteoclastic process of NFkB (39, 47, and 50). However, several studies have reported increased level of NFKB immediately after a physical activity. Schenk et al. showed that a period of physical activity prevents $\mathrm{NF} \kappa \mathrm{B}$ activity in humans, but the effect of aerobic exercise on $\mathrm{NF \kappa B}$ activity in individuals with normal glucose and insulin resistance is not clear (51). Tantiwong et al. investigated the impact of eight weeks of training on non-diabetics and showed that unlike endurance training, intense aerobic exercise increases $\mathrm{NF \kappa B}$ activity (52). Rivas et al. demonstrated that intense exercise training in the elderly leads to $60 \%$ increase in phosphorylation of the pro-inflammatory transcription factor $\mathrm{NF \kappa B}$ (53). Increased, decreased or unchanged level of $\mathrm{NF \kappa B}$ is expected after exercise, depending on the type and intensity of physical activity, fitness and early NFKB plasma level of participants and their adaptability to trainings (52). On the other hand, diabetic individuals have the highest level of NFкB activity, therefore it is likely that exercise may not increase the activity of NFkB because the threshold has been already triggered $(47,54)$. Studies also showed that using medicinal plants as a nondrug treatment is useful for the prevention of osteoporosis. Recent studies have shown that medicinal plants can prevent osteoporosis by reducing the NFאB activity. Lee et al. showed that a period of $P$. oleracea supplementation significantly reduces $\mathrm{NF \kappa B}$ and RANKL activity in postmenopausal women. They also stated that $P$. oleracea is among the medicinal plants that inhibit NFKB and prevent the osteoclastic process and osteoporosis (45).

\section{CONCLUSION}

As a non-pharmacological therapeutic approach, regular resistance training and $P$. oleracea consumption can independently increase bone formation markers and decrease bone resorption in diabetic women. However, supplementation in combination with exercise is far more effective than these two methods separately. Based on the results of this study, $P$. oleracea supplementation with resistance training is recommended for improvement of bone markers in women with type II diabetes, as a step towards reduction of bone disorders in this group of people.

\section{ACKNOWLEDGMENTS}

This article is derived from a Master's thesis (Number 95) approved by the Islamic Azad University of Sari. The authors would like to thank all those who have cooperated in this study.

\section{CONFLICT OF INTEREST}

The authors declare no conflicts of interest regarding this manuscript. 


\section{REFERENCES}

1. Ministry of Health and Medical Education. Comprehensive guide to the care of the cardiovascular system in the Islamic Republic of Iran. 14 ed: Center for Disease Control; 2005.[Persian]

2. Tahrani AA, Bailey CJ, Del Prato S, Barnett AH. Management of type 2 diabetes: new and future developments in treatment. The Lancet. 2011; 378(9786): 182-97. doi: 10.1016/S0140-6736(11)60207-9.

3. Stewart KJ. Exercise training: can it improve cardiovascular health in patient type 2 diabetes? $\mathrm{Br} \mathrm{J}$ Sports Med. 2004; 38(3): 250- 52. doi: 10.1136/bjsm.2004.012187.

4. Larijani B, Hossein-nezhad A, Rizvi SW, Munir S, Vassigh AR. Cost analysis of different Screening strategies for gestational diabetes mellitus. Endocr Pract. 2003; 9(6): 504-9. PMID:14715477.

5. Amos AF, Mccarty DJ, Zimmet P. The rising global burden of diabetes and its complication: Estimated and Projections to the year 2010. Diabetic Med. 1997; 14 Suppl 5:S1-85. PMID: 9450510.

6. Safaei H, Amini M, Janghorbani M. The effect of $H M G-C o A$ reductase inhibitor (lovastatin) on bone mineral density (BMD) in postmenopausal women with type 2 diabetes. Iranian Journal of Endocrinology and Metabolism. 2005; 7(2): 135-42. [Persian]

7. Joo Y-I, Sone T, Fukunaga M, Lim S-G, Onodera S. Effects of endurance exercise on three-dimensional trabecular bone microarchitecture in young growing rats. Bone. 2003; 33(4): 485-93. PMID:14555251.

8. Rishaug U, Birkeland K, Falch J, Vaaler S. Bone mass in non-insulin-dependent diabetes mellitus. Scandinavian journal of clinical \& laboratory investigation. 1995; 55(3): 257-62. PMID: 7638560.

9. Lipscombe LL, Jamal SA, Booth GL, Hawker GA. The Risk of Hip Fractures in Older Individuals With Diabetes A population-based study. Diabetes Care. 2007; 30(4):835-41. PMID:17392544

1. Hofbauer LC, Brueck CC, Singh SK, Dobnig H. Osteoporosis in patients with diabetes mellitus. Journal of Bone and Mineral Research. 2007; 22(9):1317-28. PMID:17501667.

11. Rahbar A, Nabipour I. The Correlation of Calcium Intake with Bone Mass Density and Bone Turn Over Markers in Adults in Bushehr Province. Iranian South Medical Journal. 2010;13(2):93-101. [Persian]

12. Montazery Fard F, Karaji Bani M, Dashipour A. The prevalence of obesity and wasting and their correlation with food intake in female junior school students in Zahedan, 2004. Iranian South Medical Journal. 2006; 9(1): 66-76. [Persian]

13. Khosla S. Minireview: The opg/rankl/rank system. Endocrinology. 2001; 142(12): 5050-5. PMID:11713196.

14. Lerner, HU. New molecules in the tumor necrosis factor ligand and receptor superfamilies with importance for physiological and pathological bone resorption. Critical Reviews in Oral Biology \& Medicine. 2004;

15(2): 64-81. PMID:1505994315. Stejskala D, Bartekb J, Pastorkováa R, Růžičkaa V, Orala I, Horalíka D. Osteoprotegerin, Rank, Rankl. Biomed. 2001; 145(2): 614.
16. West SL, Scheid JL, De Souza MJ. The effect of exercise and estrogen on osteoprotegerin in premenopausal women. Bone. 2009; 44(1): 137-44. doi: 10.1016/j.bone.2008.09.008.

17. Simonet W, Lacey D, Dunstan C, Kelley M, Chang M-S, Lüthy R, et al. Osteoprotegerin: a novel secreted protein involved in the regulation of bone density. Cell. 1997; 89(2): 309-19.

18. Kostenuik PJ, Shalhoub V. Osteoprotegerin A Physiological and Pharmacological Inhibitor of Bone Resorption. Current pharmaceutical design. 2001; 7(8): 613-35.

19. Léotoing L, Wauquier F, Guicheux J, Miot-Noirault $\mathrm{E}$, Wittrant Y, Coxam V. The polyphenol fisetin protects bone by repressing $N F-\kappa B$ and $M K P-1$-dependent signaling pathways in osteoclasts. PloS one. 2013; 8(7): e68388.

20. Hayden MS, Ghosh S. Signaling to $N F-\kappa B$. Genes \& development. 2004; 18(18): 2195-224. PMID:15371334.

21. Farzanegi P. Impact of the Synchronization of portulaca oleracea and Aerobic Training on Levels of MMP 2 and MMP9 and TIMP1 in Diabetic Women Type II. Res Mol Med, 2014; 2 (2): 34-39.

22. Bergström I, Parini P, Gustafsson SA, Andersson G, Brinck J. Physical training increases osteoprotegerin in postmenopausal women. Journal of bone and mineral metabolism. 2012; 30(2): 202-7. doi: 10.1007/s00774011-0304-6.

23. Kwon HR, Min KW, Ahn HJ, Seok HG, Lee JH, Park GS, et al. Effects of Aerobic Exercise vs. Resistance Training on Endothelial Function in Women with Type 2 Diabetes Mellitus. Diabetes Metab J. 2011; 35(4): 364-73. doi: 10.4093/dmj.2011.35.4.364.

24. Colletti LA, Edwards J, Gordon L, Shary J, Bell NH. The effects of muscle-building exercise on bone mineral density of the radius, spine, and hip in young men. Calcified tissue international. 1989; 45(1): 12-4.

25. Maddalozzo G, Snow C. High intensity resistance training: effects on bone in older men and women. Calcified tissue international. 2000; 66(6): 399-404.

26. Gardner MJ, Demetrakopoulos D, Shindle MK Griffith MH, Lane JM. Osteoporosis and skeletal fractures. HSS Journal. 2006; 2(1): 62-9.

27. Valizadeh N, Zakeri H, Shafiee A, Sarkheil P, Heshmat R, Larijani B. The Effect of Nigella Sativa Extract on Biochemical Bone Markers in Osteopenic Postmenopausal Women. Iranian Journal of Endocrinology and Metabolism. 2009; 10(6): 571-80. 28. Salehi A, Farzanegi P. Effect of 8 weeks of resistance training with and without portulacalo seeds on some of liver injury markers in women with diabetes type 2 . The Journal of Urmia University of Medical Sciences. 2015; 25(11): 968-78.[Persian]

29. Farzanegi P, Akbari A, Azarbayjani MA. Effect of Portulaca oleracea Seeds on the Levels of Matrix Metalloproteinase 2, 9 and Tissue Inhibitor Matrix Metalloproteinase 1 in Patients with Type 2 Diabetes. Modares J of Med Sci: Pathobiology. 2013; 16(2): 65-73. [Persian] 
30. Farzanegi P, Shaerani M, Azabaijani MA. Protective effects of purslane seed (Portulaca Oleracea L.) on plasma levels of Cystatin C, Cathepsin S, and Creatinine in women with type 2 Diabetes. Hormozgan Medical Journal. 2015; 19(1): 1-9.[Persian]

31. Mohamed - 1 Kotb El-sayed. Effects of Portulaca oleracea $L$. seeds in treatment of type-2 diabetes mellitus Patients as adjunctive and alternation therapy. Ethnopharmacology. 2011; 137(1): 643-51. doi:10.1016/j.jep.2011.06.020.

32. Akhoundzade Sh. Encyclopedia of Herbs. 2 ed. Tehran: Arjmand; 2009. 34-55 p. [Persian]

33. Cao D, Zheng Y, Qin L, Han T, Zhang H, Rahman K, et al. Curculigo orchioides, a traditional Chinese medicinal plant, prevents bone loss in ovariectomized rats. Maturitas. 2008; 59(4): 373-80. doi: 10.1016/j.maturitas.2008.03.010.

34. Vahedi M, Farzanegi P.The Effect of Portulacaoleracea L Consumption and Regular Exercise on Levels of Cathepsin S, Cystatin C And C-Reactive Protein in Diabetic Women. MLJGOUMS 2015; 9(4):4753.

35. Moghimi N, Rahimi E, Derakhshan S, Farhadifar F. Osteoporosis in postmenopausal diabetic women; prevalence and related factors. Iranian Journal of Nuclear Medicine. 2008;16(2):28-33. [Persian]

36. Haghighi A, Hadaegh F, Ghoreifinegadian AR. Evaluation of Bone Mineral Density in Postmenopausal Women With Type 2 Diabetes Mellitus. Razi Journal of Medical Sciences. 2009; 16(62): 113-9. [Persian]

37. Wang PS, Solomon DH, Mogun H, Avorn J. HMGCoA reductase inhibitors and the risk of hip fractures in elderly patients. Jama. 2000; 283(24): 3211-6. PMID: 10866868

38. Yasuda H, Shima N, Nakagawa N, Mochizuki S-I, Yano K, Fujise N, et al. Identity of Osteoclastogenesis Inhibitory Factor (OCIF) and Osteoprotegerin (OPG): A Mechanism by which OPG/OCIF Inhibits Osteoclastogenesis in Vitro 1. Endocrinology. 1998; 139(3): 1329-37.

39. Bergström I, Landgren B, Brinck J, Freyschuss B. Physical training preserves bone mineral density in postmenopausal women with forearm fractures and low bone mineral density. Osteoporosis International. 2008; 19(2): 177-83. PMID:17768587.

40. Bergström I, Lombardo C, Brinck J. Physical training decreases waist circumference in postmenopausal borderline overweight women. Acta obstetricia et gynecologica Scandinavica. 2009; 88(3): 308-13. doi: 10.1080/00016340802695942.

41. Saremi A. Effect of resistance training on bone mineral density and serum levels of myostatin in young men. Arak University of Medical Sciences Journal. 2009; 12(2): 89-97. [Persian]

42. Marques EA, Wanderley F, Machado L, Sousa F, Viana JL, Moreira-Gonçalves D, et al. Effects of resistance and aerobic exercise on physical function, bone mineral density, OPG and RANKL in older women. Experimental Gerontology. 2011; 46(7): 524-32. doi: 10.1016/j.exger.2011.02.005.

43. Gao Z, Hwang D, Bataille F, Lefevre M, York D, Quon MJ, et al. Serine phosphorylation of insulin receptor substrate 1 by inhibitor $\kappa B$ kinase complex.
Journal of Biological Chemistry. 2002; 277(50): 4811521.

44. Li F, Li Q, Gao D, Peng Y, Feng C. Preparation and antidiabetic activity of polysaccharide from Portulaca oleracea L. African Journal of Biotechnology. 2009; 8(4): 569-573.

45. Lee AS, Lee YJ, Lee SM, Yoon JJ, Kim JS, Kang DG, et al. An aqueous extract of Portulaca oleracea ameliorates diabetic nephropathy through suppression of renal fibrosis and inflammation in diabetic $d b / d b$ mice. The American journal of Chinese medicine. 2012; 40(03): 495-510.

46. Ng CJ, Wadleigh DJ, Gangopadhyay A, Hama S, Grijalva VR, Navab M, et al. Paraoxonase-2 is a ubiquitously expressed protein with antioxidant properties and is capable of preventing cell-mediated oxidative modification of low density lipoprotein. Journal of Biological Chemistry. 2001; 276(48): 44444-9. PMID:11579088.

47. Austin RL, Rune A, Bouzakri K, Zierath JR, Krook A. siRNA-mediated reduction of inhibitor of Nuclear Factor- $\kappa B$ Kinase prevents Tumor Necrosis Factor- $\alpha-$ induced insulin resistance in human skeletal muscle. Diabetes. 2008; 57(8): 2066-73.

48. Feng X. RANKing intracellular signaling in osteoclasts. IUBMB life. 2005; 57(6): 389-95.

49. Theoleyre S, Wittrant Y, Tat SK, Fortun Y, Redini F, Heymann D. The molecular triad OPG/RANK/RANKL: involvement in the orchestration of pathophysiological bone remodeling. Cytokine \& growth factor reviews. 2004; 15(6): 457-75.

50. Armstrong AP, Tometsko ME, Glaccum M, Sutherland CL, Cosman D, Dougall WC. A RANK/TRAF6-dependent signal transduction pathway is essential for osteoclast cytoskeletal organization and resorptive function. Journal of Biological Chemistry. 2002; 277(46): 44347-56.

51. Schenk S, Horowitz JF. Acute exercise increases triglyceride synthesis in skeletal muscle and prevents fatty acid-induced insulin resistance. Journal of Clinical Investigation. 2007; 117(6): 1690.

52. Tantiwong $\mathrm{P}$, Shanmugasundaram K, Monroy A, Ghosh S, Li M, DeFronzo RA, et al. $N F-\kappa B$ activity in muscle from obese and type 2 diabetic subjects under basal and exercise-stimulated conditions. American Journal of Physiology-Endocrinology and Metabolism. 2010; 299(5):E794-E801.

53. Rivas DA, Morris EP, Haran PH ,Pasha EP, da Silva Morais M, Dolnikowski GG, et al. Increased ceramide content and $N F \kappa B$ signaling may contribute to the attenuation of anabolic signaling after resistance exercise in aged males. Journal of Applied Physiology. 2012; 113(11): 1727-36

54. Friedrichsen M, Ribel-Madsen R, Wojtaszewski J, Grunnet L, Richter EA, Billestrup N, et al. Dissociation between skeletal muscle inhibitor- $\kappa B$ kinase/nuclear factor- $\kappa B$ pathway activity and insulin sensitivity in nondiabetic twins. The Journal of Clinical Endocrinology \& Metabolism. 2010; 95(1): 414-21. DOI: http://dx.doi.org/10.1210/jc.2009-1147. 